\begin{tabular}{|c|c|c|}
\hline $\begin{array}{l}\text { PKS } \\
\text { PUBLIC } \\
\text { KNOLLEDGE } \\
\text { PROJECT }\end{array}$ & $\begin{array}{c}\text { REVISTA DE GEOGRAFIA } \\
\text { (RECIFE) } \\
\text { http://www.revista.ufpe.br/revistageografia }\end{array}$ & $\begin{array}{l}\text { OJS } \\
\text { OPEN } \\
\text { JOENAL } \\
\text { SYYSTEMS }\end{array}$ \\
\hline
\end{tabular}

\title{
AVALIAÇÃO DA TEMPERATURA APARENTE DE SUPERFÍCIE NA ZONA CENTRAL DE UMUARAMA, PARANÁ NO PERÍODO DE 22/04/2013 À 25/04/2014
}

\author{
Renan Valério Eduvirgem ${ }^{1}$, Paulo José Moraes Monteiro e Teixeira Germano ${ }^{2}$ \\ ${ }^{1}$ Doutorando em Geografia na Universidade Estadual de Maringá. E-mail: georenanvalerio@gmail.com \\ ${ }^{2}$ Doutorando em Geografia na Universidade Estadual de Maringá. E-mail: paulojosegermano@gmail.com
}

Artigo recebido em 01/03/2017 e aceito em 30/08/2018

\begin{abstract}
RESUMO
O presente trabalho tem o propósito de identificar a variação da temperatura aparente de superfície na Zona Central da cidade de Umuarama, Paraná, concomitante as suas relações com a atual morfologia urbana. As temperaturas da área de estudo (Zona Central) foi analisada por meio da utilização de imagens do satélite Landsat 8, banda 10 (infravermelho termal) correspondente ao período 22/04/2013 à 25/04/2014. Ao chegar aos resultados é possível afirmar que as imagens de satélites proporcionam dados referentes as temperaturas de superfícies da área estudada, na qual foi possível averiguar diferentes temperaturas, como também pontos discrepantes, devido à distribuição da vegetação urbana e a configuração morfológica. Com os dados obtidos neste estudo, foi possível concluir que a vegetação viária, praças e a morfologia urbana, são os agentes que proporcionam valores de temperaturas de superfície heterogêneas na Zona Central.
\end{abstract}

Palavras-chave: Geografia; Sensoriamento Remoto; Infravermelho Termal; Temperatura Aparente de Superfície; Geotecnologias.

\section{AN EVALUATION OF THE APPARENT SURFACE TEMPERATURE IN THE CENTRAL ZONE OF UMUARAMA, PARANÁ STATE, FROM APRIL 22ND, 2013 TO APRIL 25TH, 2014}

\begin{abstract}
This work aims to identify the variation of the apparent surface temperature in the Central Zone of Umuarama, a city located in Paraná state, concomitant with its relations with the current urban morphology. The temperatures of the studied area (the Central Zone) were analyzed using the images of the satellite Landsat 8 , with corresponding band 10 (thermal infrared) in the period from 22/04/2013 to 25/04/2014. At the results section it is possible to affirm that the satellite images provide data regarding the surface temperatures of the studied area, in which it was possible to ascertain different temperatures, as well as discrepant points, due to the distribution of the urban vegetation and the morphological configuration. With the obtained data from this study, it was possible to conclude that the road vegetation, squares and urban morphology are the agents that provide values of heterogeneous surface temperatures in the Central Zone.
\end{abstract}

Keywords: Geography; Remote sensing; Thermal Infrared; Apparent Surface Temperature; Geotechnology. 


\section{INTRODUÇÃO}

Com relação à análise de temperaturas, especificamente no que tange as ilhas de carlor, o primeiro estudo foi realizado na cidade de Londres em 1818 pelo meteorologista Luke Howard. Gartland (2010) pauta que Luke Howard, verificou disparidade entre a temperatura da área rural comparada com a área urbana.

Já no tocante as abordagens sobre ilhas de calor têm-se, na década de 1950, nos Estados Unidos da América (EUA), os estudos do pesquisador Mitchell, tendo como maiores destaques os trabalhos intitulados: "On the causes of instrumentally observed secular temperature trends" tendo continuidade por: "The temperature of cities" (GERMANO, 2012).

A primeira pesquisa no Brasil relacionada ao clima urbano foi desenvolvida por Carlos Augusto de Figueiredo Monteiro sendo resultante desta a tese intitulada "Teoria e clima urbano", defendida em 1975 e editada no ano seguinte. Conforme este mesmo autor em pesquisas em anos posteriores o clima urbano demonstra-se como sistema complexo, adaptativo e aberto sendo especifico para cada ambiente urbano, pois cada ambiente possui sua característica única, concomitante às alterações climáticas (MONTEIRO, 2003).

O clima urbano resulta das modificações que as superfícies, materiais e as atividades das áreas urbanas provocam nos balanços de energia, massa e momentum. (LANDSBERG, 1981; OKE, 1987; 1988; KUTTLER, 1988 e ARNFIELD, 2003).

A ascensão da temperatura na área central ocorre em virtude das alterações no particionamento da energia entre fluxo de calor latente e sensível, outrossim, as áreas com concreto cobrindo o solo, malha asfáltica, emissão de gases poluentes e da pouca e vegetação. Todos esses fatores elevam a média térmica, sendo potencializado pelas edificações que dificultam a penetração dos ventos. A disparidade da temperatura pode atingir de $6^{\circ} \mathrm{C}$ a $8^{\circ} \mathrm{C}$, entre cidades e seus arredores (SZINVELSKI, 2005). Tais elementos e fatores são influentes na geração das ilhas de calor, que são bolsões de ar quente, resultante do aumento de temperaturas médias.

Frequentemente as ilhas de calor estão localizadas na área urbana, pelo fato de haver padrão adensado de construções, concomitante aos elementos de baixo albedo, ocorrendo assim, maior absorção da radiação solar incidente (RSI) em relação à refletância. Segundo Lombardo (1985) a concentração de gases e materiais particulados são responsáveis pelo efeito estufa, ocorre em escala superior na atmosfera das áreas centrais das cidades, retendo-se 
assim mais calor. Esta concentração, somada a quantidade de veículos que circulam na área central, aumenta o fenômeno da ilha de calor.

Nos estudos de Ilhas de calor e temperatura aparente da superfície é fundamental compreender a climatologia para que possa facilitar na compreensão dos resultados, pois pode ocorrer correlação entre os dados. Deste modo, neste trabalho será analisada a temperatura aparente da superfície.

Consideramos como fundamental, para o melhor entendimento de nossas considerações, a compreensão do conceito de radiação eletromagnética, pois segundo Tubelis e Nascimento (1984), radiação solar é a energia recebida pela Terra via ondas eletromagnéticas. Os autores ainda salientam que do total de $100 \%$ da energia do sol que chega à atmosfera, cerca de $40 \%$ incide sobre as nuvens, e somente $1 \%$ é absorvido e $25 \%$ é refletido e perdem-se no espaço, chegando à superfície somente $14 \%$. Dos $60 \%$ que não incidiram sobre as nuvens, $7 \%$ são refletidos por aerossóis e $16 \%$ são absorvidos por gases atmosféricos, chegando $37 \%$ à superfície. Dos 51\% que chegam à superfície, 5\% diminuemse, pois são refletidos pela própria superfície. Deste modo, aproximadamente $46 \%$ da energia é absorvida pela superfície.

A radiação espalhada, refletida e absorvida, gera a temperatura aparente da superfície, discrepante entre área urbana e área rural, pois a energia emitida pelos alvos é imprescindível para as imagens termais de modo que cada alvo possui seu potencial peculiar de adquirir calor.

Conforme Gartland (2010) dois fatores são essenciais para que ocorra a mudança de temperatura das áreas urbanas. O primeiro fator passa por influências dos materiais de construção, devido à impermeabilidade e estanqueidade, e por este fato, não dispondo de umidade suficiente para dispersar o calor. O segundo fator é a tonalidade escura de materiais utilizados nas edificações que possuem maior capacidade de absorção e retenção de energia solar. Os fatores levantados permitem a formação de ilhas de calor, pois a excitação das partículas gera calor, que poderá ser irradiado em forma de ondas longas, aquecendo o ar sobre elas, deste modo podendo provocar anomalias climáticas locais, ocorrendo pontos com temperatura mais elevadas que em outros pontos de uma mesma área.

Garcia (1996) utiliza uma escala para classificação das temperaturas por intervalo, a escala utilizada por este autor refere-se à classificação das anomalias de temperatura entre áreas heterogêneas e por intervalo. Assim, o autor estabeleu da seguinte maneira: $0^{\circ} \mathrm{C}$ a $2^{\circ} \mathrm{C}$ considerada fraca, de $2^{\circ} \mathrm{C}$ a $4^{\circ} \mathrm{C}$ média, de $4^{\circ} \mathrm{C}$ a $6^{\circ} \mathrm{C}$ forte e maior que $6^{\circ} \mathrm{C}$ muito forte. As 
temperaturas aparentes da superfície variam de cidade para cidade, pelo fato que cada uma possui suas peculiaridades.

O planejamento urbano pode ser auxiliado por estudos de temperatura aparente de superfície. Esses estudos são essenciais, pois demonstram as localidades em que se pode melhorar a arborização e, assim, mitigar as possíveis ilhas de calor. Estudos como este, auxiliam em planos diretores municipais, no qual, promovem benefício direto para a população, como o conforto térmico agradável.

Conforme Garcia (2006) não é gerado desconforto térmico na temperatura de $25^{\circ} \mathrm{C}$, pois é considerada neutra. A cidade de Umuarama-PR apresenta temperatura média de $30,7^{\circ} \mathrm{C}$ (IAPAR, 2000) nos meses mais quentes, deste modo gerando desconforto térmico. A vegetação de grande porte, como exemplo a Sibipiruna (Caesalpinia pluviosa) da Família Fabaceae, é fundamental para atenuar a temperatura da superfície, assim, ocasionando conforto térmico agradável aos citadinos, sendo possível diminuir os gastos com energia elétrica e proporcionar paisagens agradáveis nas cidades como um todo.

Segundo Grey e Deneck (1978), uma única árvore de porte grande, hidratada pode evapotranspirar 380 litros de água por dia aproximadamente, deste modo, sendo equivalente a cinco aparelhos de ar condicionado de potencia média (10.000 BTUs), ligados por pouco menos de 24 horas, proporcionando sombra, capturando $\mathrm{CO}_{2}$ e umedecendo o ar.

Sensoriamento remoto, para Fitz (2008), é a técnica que utiliza sensores para a captação e registro a distancia, sem o contato direto, da energia refletida ou absorvida pela superfície terrestre. Deste modo é possível realizar a extração dos conteúdos das imagens de satélites por meio de técnicas, as quais podem ser tratadas por programas específicos de Geoprocessamento para que seja possível a obtenção das informações que o operador necessita, normalmente resultando em outra imagem.

Weng e Quattrochi (2003) verificaram que o sensoriamento remoto é uma ferramenta fundamental, pelo fato de que oferece visões em diferentes escalas, juntamente da diferenciação dos elementos mais quentes e frios da paisagem. Neste contexto estas abordagens são essenciais para o estudo da temperatura aparente da superfície.

As técnicas de tratamento de imagens orbitais são inúmeras, podemos citar como exemplo as correções para efeitos atmosféricos, emissividade superficial, rugosidade superficial, anisotropia e, a temperatura aparente de superfíicie que permite realizar a conversão dos dados coletados pelo satélite Landsat 8 na banda 10 (infravermelho termal), em temperatura aparente da superfície, para assim, obter as diferenças térmicas. 
Deste modo, o presente trabalho apresentará as análises de temperatura da superfície no sítio urbano de Umuarama-PR, correspondente ao período de 22/04/2013 à 25/04/2014, na Zona Central. Esta área foi escolhida devido as diferentes configurações da morfologia urbana, sendo provável a ocorrência de ambientes microclimáticos diferentes.

\section{METODOLOGIA}

Para atender os objetivos aplicados da pesquisa, foram adquiridas imagens da área de estudo no sítio da United States Geological Survey (USGS) correspondente ao período 22/04/2013 à 25/04/2014, totalizando 21 imagens.

Após a aquisição das imagens foi realizada a verificação deste material, para descartar as imagens que apresentaram recobrimento por nuvens na área de estudo. Do total das imagens, 06 foram descartadas. As estações trabalhadas foram de outono, inverno, primavera e verão, deste modo foi possível demonstrar as temperaturas baixas e as mais elevadas.

Para obter os valores de temperatura de superfície foi utilizado o software QGIS (Quantum GIS. Development Team, 2012). Os dados de entrada foram as imagens do satélite Landsat 8 na banda 10 (infravermelho termal), em seguida realizou-se o processamento das imagens, de modo que o cômputo da radiância espectral de cada banda, onde ocorre a efetivação da calibração radiométrica, em que o número digital (ND) de cada pixel da imagem é convertido em radiância espectral monocromática. Na banda 10, denominada termal, a radiância representa a energia emitida por cada pixel. Em seguida os valores de radiância foram convertidos à reflectância aparente, e desta maneira, foi possível a aquisição dos valores de temperatura.

$\mathrm{Na}$ determinação da temperatura de superfície foi utilizado o guia empregado pelo Center for Earth Observation, da Universidade de Yale. Este método possui embasamento na Lei de Planck.

A Lei de Planck tem como propósito geral, explicar que todas as superfícies emitem energia térmica, no máximo de energia que é possível ser emitida por uma superfície perfeita, podendo ser considerado um corpo negro. Trata-se de um corpo hipotético que pode absorver e emitir a radiação eletromagnética em todos os comprimentos de onda de forma isotrópica, que pode ser produzida como a quarta potência da temperatura de superfície do objeto (Equação 1). 
Energia emitida por um corpo negro $=\sigma \mathrm{T} 4$

Onde "б" constante de Stefan-Boltzmann (5,67 x 10-8 W/m2 k4).

Todavia, como nenhuma superfície real se comporta como um corpo negro, deve-se considerar a seguinte fórmula (Equação 2).

Energia real emitida $=\varepsilon \sigma \mathrm{T} 4$

Onde " $\varepsilon ":$ emissividade da superfície, que varia entre 0 e 1.

Os elementos presentes na terra apresentam emissões que variam de 0,8 a 0,95 . Sendo alguns materiais como metais, sem revestimento, podem apresentar valores variando de 0,2 a 0,6 .

Para ser possível a obtenção dos valores de temperatura da superfície, foi utilizado o tutorial da Universidade de Yale o Center for Earth Observation disponível em: <https://yceo.yale.edu/faqs/landsat>, que apresenta duas formulas, sendo a primeira responsável pela transformação dos valores ND (números digitais coletados via satélite), que vão de 0 (branco) a 255 (preto), em valores de radiância (Equação 3).

CVR1 = gain $. \mathrm{ND}+$ bias

Onde:

CVR1 $=>$ Valor de radiância do pixel

gain $=>$ Coeficiente de calibração termal $(0.05518)$

ND $=>$ Número Digital ( 0 a 255)

Bias $=>$ Coeficiente de calibração (1.2378)

Os valores de bias e gain são oriundos da calibração dos sensores, que interferem diretamente nos dados de temperatura. Ao final do lançamento dos dados ND para radiância, aplicou-se a fórmula (Equação 04) para transformação dos valores em temperatura, cujos resultados foram expressos em graus Celsius. 
$T=\frac{K_{2}}{\operatorname{In}\left(\frac{K_{1 \gamma s}}{C V R_{1}}\right)+1}-273,15$

Onde:

$\mathrm{T}=>$ Temperatura em Kelvin

CVR1 => Valor de radiância dos pixels da imagem anterior

$\varepsilon=>$ Emissividade (foi adotado o valor de 0.95 )

K1 607.76 => Constante de calibração

K2 1260.56 => Constante de calibração

Para tornar possível o êxito no resultado final foi elaborada uma tabela com os valores máximos, mínimos, amplitude e média geral das temperaturas obtidas, facilitando a explanação das localidades que apresentaram as temperaturas mais elevadas, sendo explanada no decorrer deste trabalho. Para que deste modo este trabalho possa futuramente auxiliar na tomada de decisão e gestão urbana da cidade.

\section{LOCALIZAÇÃO DE UMUARAMA, PARANÁ, E ÁREA DE ESTUDO}

A cidade de Umuarama está localizada na região sul do Brasil, no noroeste do estado do Paraná a aproximadamente $593 \mathrm{~km}$ da capital do Estado, Curitiba (Figura 1). A área total municipal é de $1.232 \mathrm{Km} 2$, a população estimada é de 109.955 habitantes (IBGE, 2018).

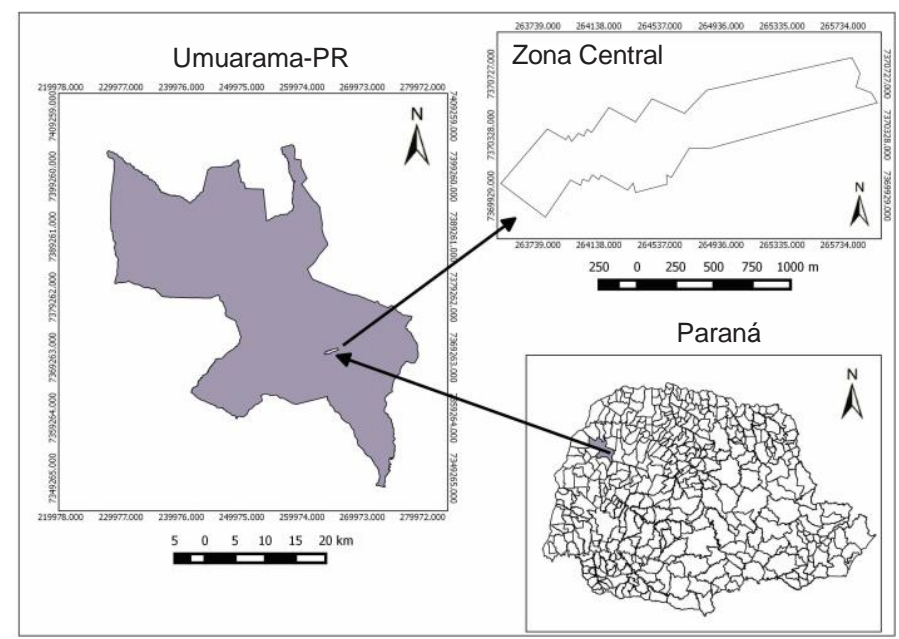

Figura 1 - Localização de Umuarama, Paraná, e área de estudo.

Fonte: ITCG (2015) - SIRGAS (2000)

Elaboração: Renan Valério Eduvirgem 
O clima da região, de acordo com o método de Köeppen é classificado como Cfa, clima subtropical úmido mesotérmico. Segundo os dados do IAPAR (2000) as temperaturas médias nos meses quentes são superiores aos $22^{\circ} \mathrm{C}$ e nos meses mais frios são inferiores a $18^{\circ} \mathrm{C}$, ocorrendo geadas com pouca frequência na estação de inverno. No que concerna a precipitação pluvial, os regimes anuais oscilam entre 1200 a $1600 \mathrm{~mm}$, sendo bem distribuidas, no entanto, com concentração das chuvas nos meses de dezembro, janeiro e fevereiro. A classificação do IBGE (2002) complementa ainda que, o município é subquente e pode ocorrer de 1 a 2 meses seco.

Os aspectos litológicos são oriundos do arenito da Formação Caiuá. A cidade está situada no Terceiro Planalto Paranaense (MAACK, 1968), apresentando genericamente um relevo suave a suave-ondulado com as cotas altimétricas em torno de 480 metros.

Deste modo, de acordo com os estudos de (MAACK, 1968) referente às cotas altimétricas, o município de Umuarama, apresenta variações de 250 a 450 metros (Figura 2). Assim, concordando com Maack no que tange a caracterização do relevo como suave a suaveondulado.

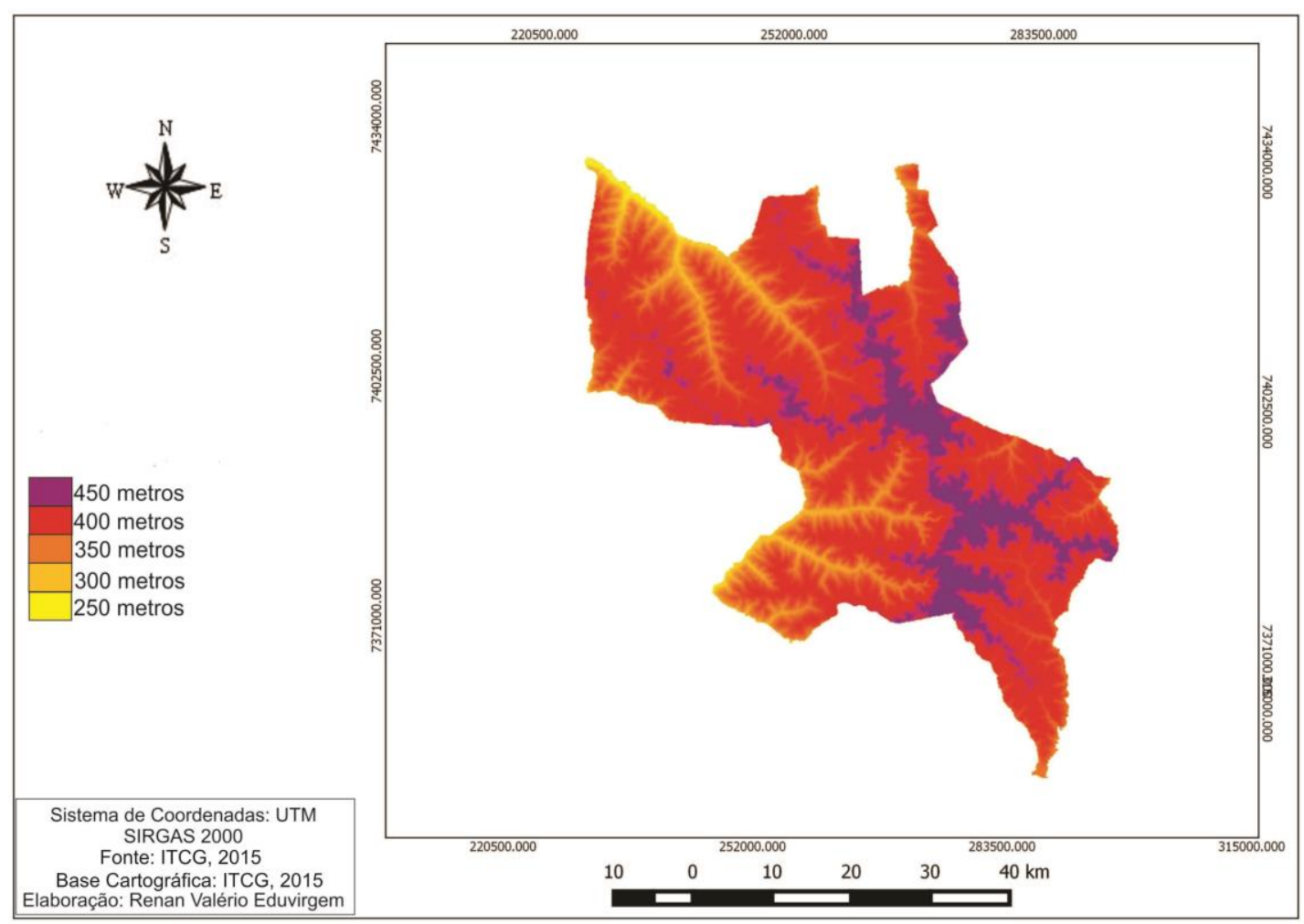

Figura 2 - Hipsometria de Umuarama, Paraná Fonte: ITCG (2015)

Elaboração: Renan Valério Eduvirgem 
Descrição da Zona Central

A Zona Central está localizada na porção central da cidade. Com relação ao uso e ocupação do solo, pode-se iniciar pelas praças: Oscar Thompson Filho, Santos Dumont e Arthur Thomas (Figura 3), estas praças têm como propósito realçar a beleza da cidade, tendo também a função de auxiliar no arrefecimento das temperaturas elevadas, pois a Zona Central (ZC) possui malha asfáltica, calçamento, além de, totalmente construída com edificações, instalações comerciais e entre outras, assim, havendo poucos terrenos baldios na Zona Central.

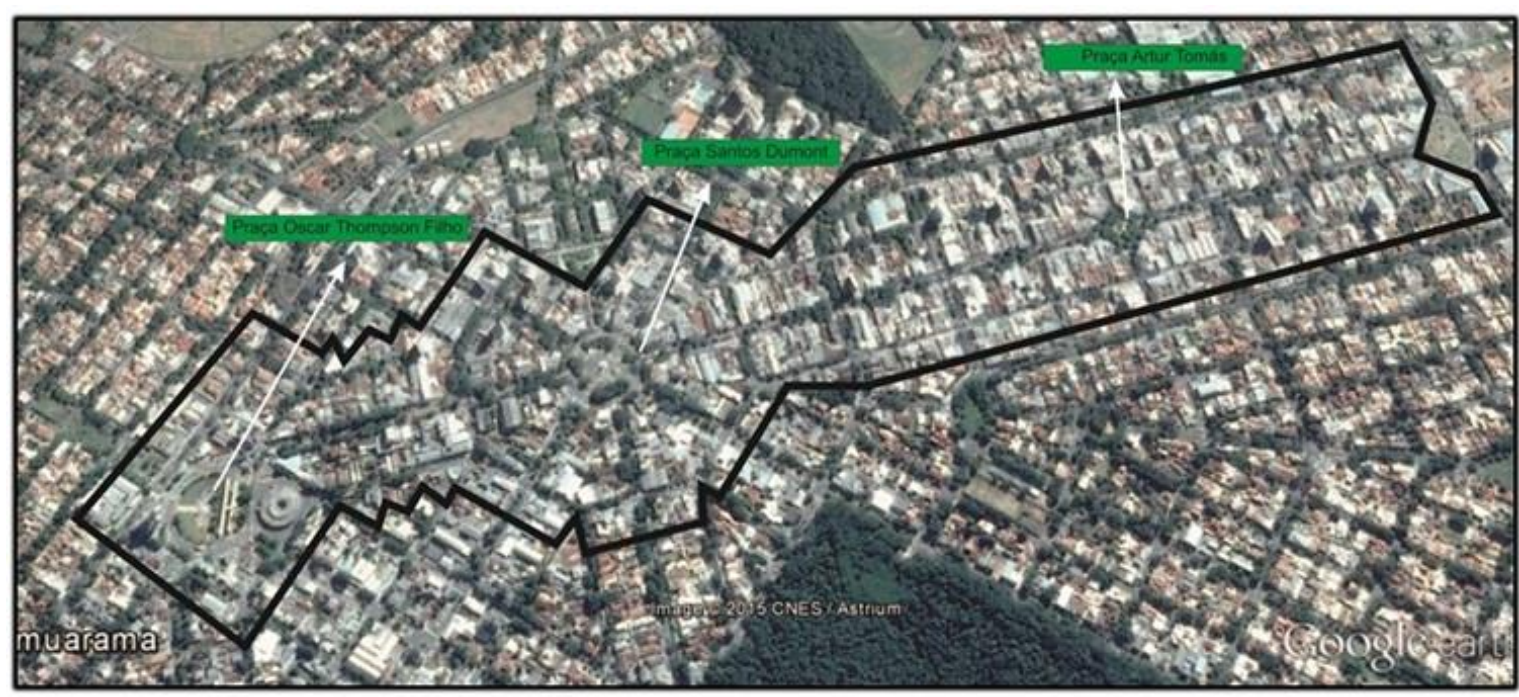

Figura 3 - Zona Central de Umuarama com destaques as praças Base: Google Earth (2015)

Elaboração: Renan Valério Eduvirgem

A ZC em suma, é dotada de comércios de gênero alimentícios, combustíveis, roupas, calçados, artesanato, farmácias, joalherias e dentre outros ramos comercial no setor de bens e serviços. Devido ao comércio existente na ZC a circulação de veículos é intensa durante todo o dia, os veículos auxiliam no aumento da temperatura de superfície, pois a alta temperatura que sai dos motores penetram por condução na malha asfaltica. No entanto parte das vias de tráfego da área de estudo possui boa arborização, que contribuem para o arrefecimento da temperatura. 


\section{RESULTADOS E DISCUSSÕES}

Nas análises realizadas por meio das 15 imagens correspondentes ao período de 22/04/2013 à 25/04/2014, enquadrando as 04 estações do ano (outono, inverno, primavera e verão), permitiu verificar que na Zona Central ocorre a variação da temperatura de superfície.

Foi possível observar que as temperaturas da $\mathrm{ZC}$ apresentaram mínima de $14^{\circ} \mathrm{C}$ e máximo de $38^{\circ} \mathrm{C}$. A amplitude térmica foi de $4^{\circ} \mathrm{C}$ para todas as imagens e, a média geral foi de $25,1^{\circ} \mathrm{C}$. É possível observar que a mínima registrada, foi no dia 27/07/2013, no qual a temperatura mínima de superfície registrada foi de $14^{\circ} \mathrm{C}$, entretanto a máxima mais alta registrada, foi na data de 13/09/2013, com a temperatura de $33,5^{\circ} \mathrm{C}$, sendo estes valores os valores extremos registrados neste estudo (Tabela 1 ).

Tabela 1 - Dados gerais de temperaturas da Zona Central

\begin{tabular}{c|c|c|c|c}
\hline Imagens & $\begin{array}{c}\text { Mínima } \\
\left({ }^{\circ} \mathrm{C}\right)\end{array}$ & $\begin{array}{c}\text { Máxima } \\
\left({ }^{\circ} \mathrm{C}\right)\end{array}$ & $\begin{array}{c}\text { Amplitude } \\
\left({ }^{\circ} \mathrm{C}\right)\end{array}$ & $\begin{array}{c}\text { Média de temperatura da imagem } \\
\left({ }^{\circ} \mathrm{C}\right)\end{array}$ \\
\hline $22 / 04 / 2013$ & 22,0 & 26,0 & 4 & 24,0 \\
\hline $09 / 06 / 2013$ & 18,5 & 22,5 & 4 & 20,5 \\
\hline $11 / 07 / 2013$ & 19,5 & 23,5 & 4 & 21,5 \\
\hline $27 / 07 / 2013$ & 14,0 & 18,0 & 4 & 16,0 \\
\hline $12 / 08 / 2013$ & 17,0 & 21,0 & 4 & 19,0 \\
\hline $28 / 08 / 2013$ & 15,0 & 19,0 & 4 & 17,0 \\
\hline $13 / 09 / 2013$ & 29,5 & 33,5 & 4 & 31,5 \\
\hline $31 / 10 / 2013$ & 28,0 & 32,0 & 4 & 30,0 \\
\hline $18 / 12 / 2013$ & 29,0 & 33,0 & 4 & 31,0 \\
\hline $19 / 01 / 2014$ & 29,0 & 33,0 & 4 & 36,0 \\
\hline $04 / 02 / 2014$ & 34,0 & 38,0 & 4 & 27,5 \\
\hline $08 / 03 / 2014$ & 25,5 & 29,5 & 4 & 26,0 \\
\hline $24 / 03 / 2014$ & 24,0 & 28,0 & 4 & 24,5 \\
\hline $09 / 04 / 2014$ & 22,5 & 26,5 & 4 & 22,0 \\
\hline $25 / 04 / 2014$ & 20,0 & 24,0 & 4 & 25,1 \\
\hline $\begin{array}{c}\text { Média } \\
\text { geral }\left({ }^{\circ} \mathrm{C}\right)\end{array}$ & 23,1 & 27,1 & 4 & 4 \\
\hline
\end{tabular}

Elaborado por: Renan Valério Eduvirgem

Para facilitar a compreensão da Tabela 1 foi elaborado um gráfico (Figura 4) para explanar as informações de maneira mais simplificada para melhor compreensão. 


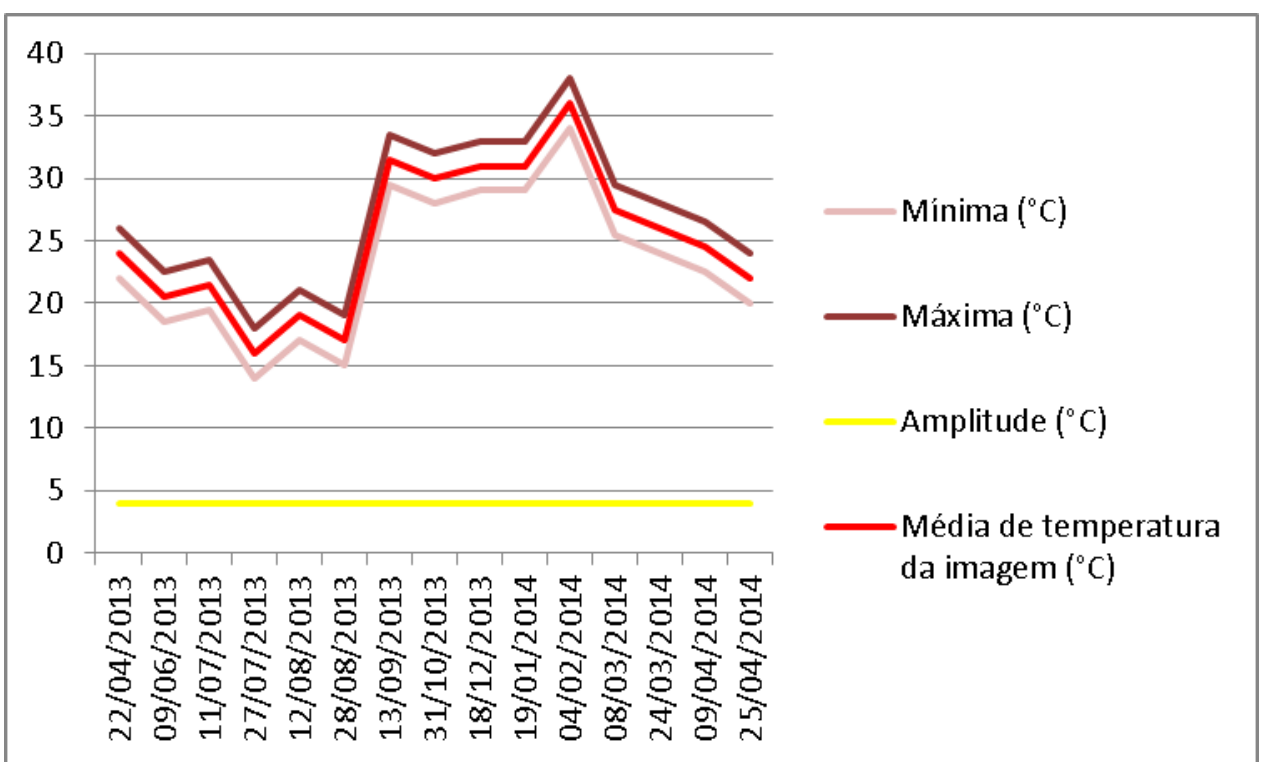

Figura 4 - Gráfico dos dados de temperaturas da Zona Central Elaborado por: Renan Valério Eduvirgem

Após extrair os valores de temperatura por meio do processamento das imagens, tornou-se possível a observação, distribuição e ocorrência das discrepâncias na ZC de Umuarama. Para facilitar a compreensão dos valores e localdiades com temperaturas de superfícies heterogêneas foram criadas 05 classes sendo: Muito baixa; Baixa; Média; Alta, Muito alta (Figura 5 e 6 ). 


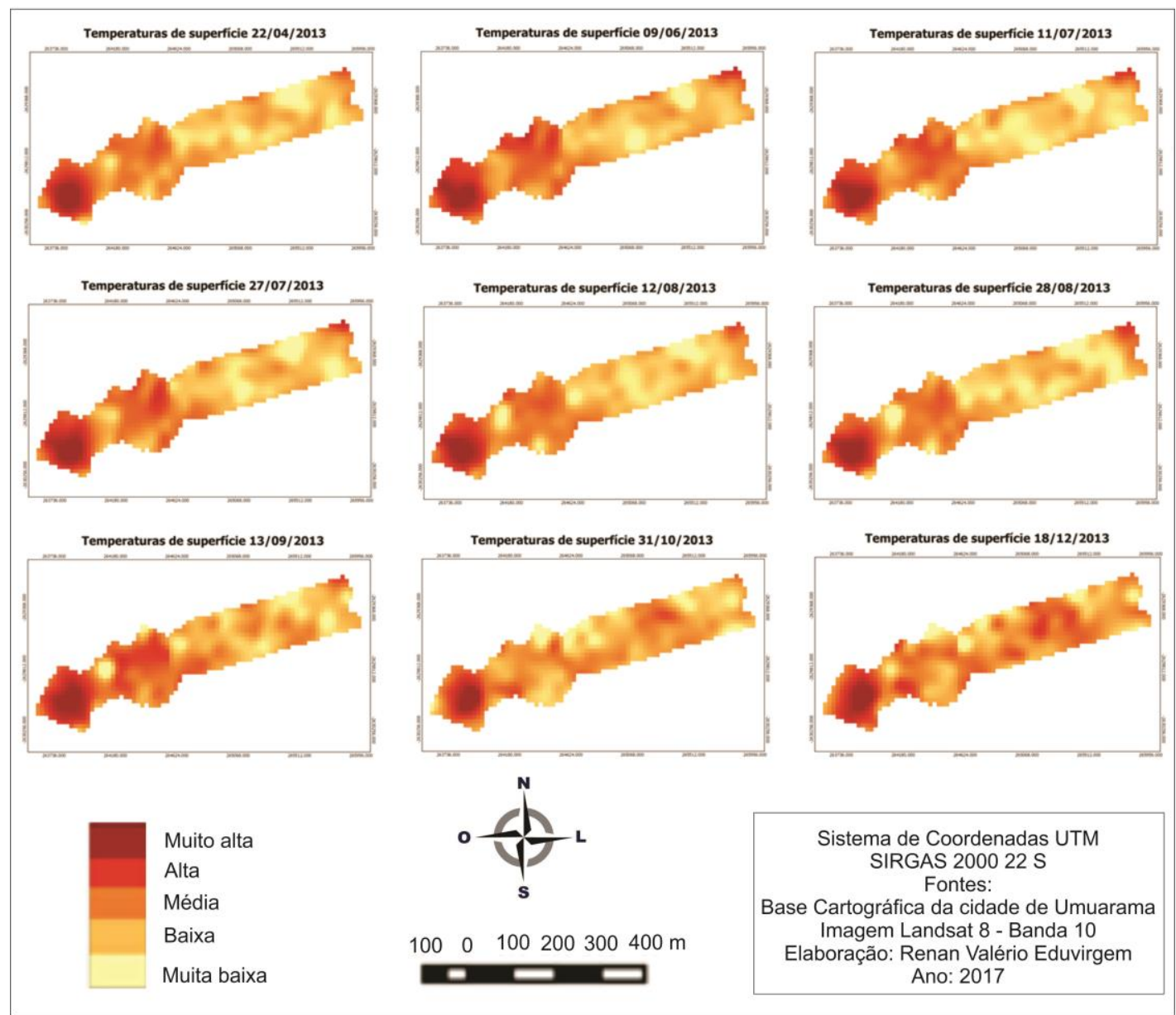

Figura 5 - Mapas termais da Zona Central correspondente o período de 22/04/2013 a 18/12/2013

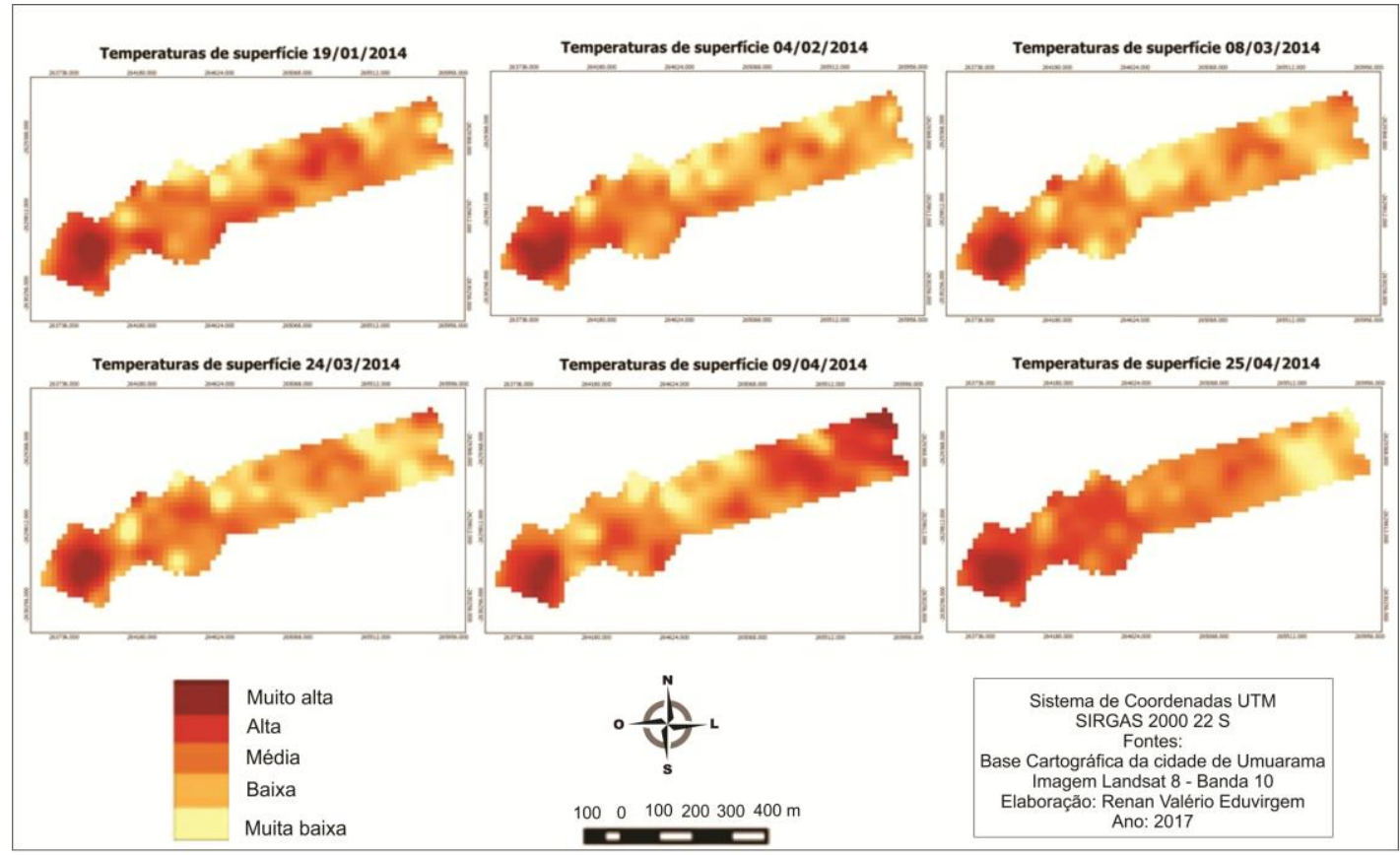

Figura 6 - Mapas termais da Zona Central correspondente o período de 19/01/2014 a 25/04/2014 
Em relação às localidades, é possível notar que a região mais quente da área de estudo está localizada na porção oeste dos mapas, onde se localiza a Praça Oscar Thompson Filho, local com déficit de arborização e pequena área com gramíneas. Neste ponto também está localizado o terminal de transporte coletivo e, a rodoviária.

O primeiro possui telhado de aço galvanizado, já o segundo possui telhado de fibrocimento, favorecendo assim, o aumento das temperaturas dos alvos. Nesta parte da área de estudo a malha asfáltica e as calçadas também favorecem o aumento das temperaturas de superfície.

A Praça Santos Dumont também contempla pouca arborização e possui em seus arredores densa urbanização, calçamentos, malha asfáltica e intensa circulação de veículos na malha urbana radial reticulada. Entretanto, a Praça Santos Dummont é privilegiada, pois possui entroncamento de várias vias urbanas, com arborização, este fator é determinante para amenizar a temperatura e, sendo um dos fatores que não permitem que os alvos destas localidades emitam energia termal na quantidade semelhante aos arredores da Praça Oscar Thompson.

A Praça Arthur Thomas possuiu arborização concentrada em relação às anteriores até o ano de 2016, em que foi realizada a revitalização, cujo retirou algumas árvores do interior da praça e implantaram estruturas metálicas (EDUVIRGEM \& FERREIRA, 2017), no entanto, as árvores no seu entorno foram mantidas, sendo este fator determinante para arrefecimento de seu entorno. No entanto, nas proximidades desta localidade existem ruas predominantemente estreitas, com a presença de telhados metálicos, denso calçamento, malha asfáltica e um pequeno trecho com prédios alinhados, com a configuração de "canyon urbano". Esses fatores aumentam os valores de temperatura de superfície no espaço (Figura $07)$.

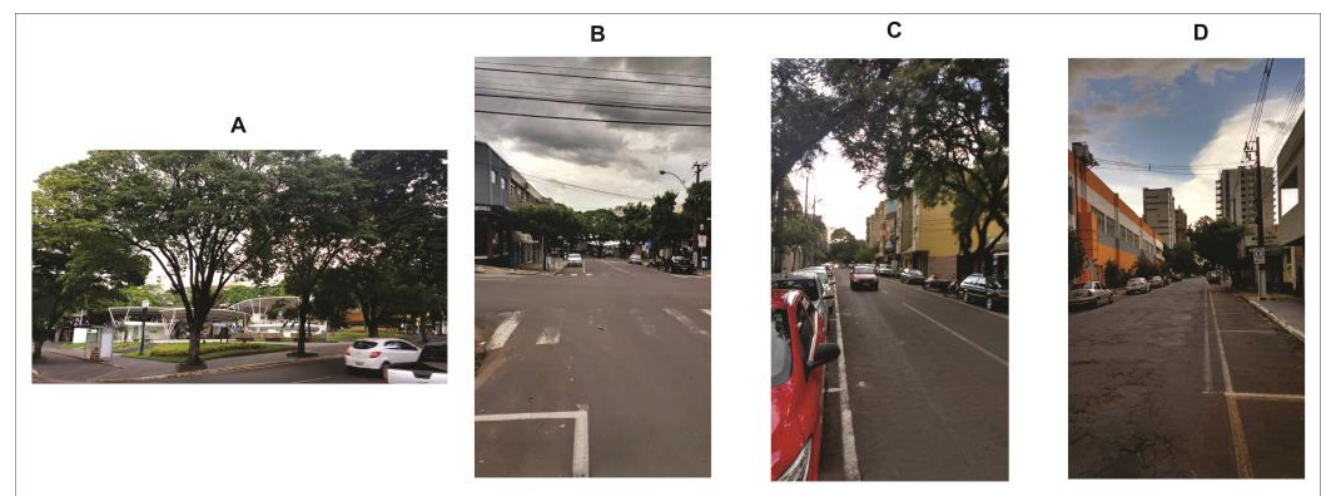

Figura 7 - A) Praça Arthur Thomas, B), C) e D) morfologia urbana nos arredores da praça Fonte: Renan Valério Eduvirgem 
Deste modo ao concretizar as análises das imagens termais foi possível verificar que a morfologia urbana da Zona Central, propiciou temperaturas de superfícies heterogêneas, como também a arborização, os materiais utilizados nas construções urbanas e no uso do solo. Todavia é imprescindível salientar que a temperatura do ar e umidade, também podem influenciar nas respostas dos alvos, assim, colaborando para as diferenças de temperaturas, como também, para os valores de máxima e mínima registrados durante o período de estudo.

Com os resultados obtidos pode-se verificar que as imagens de satélites juntamente às técnicas do Sensoriamento Remoto, permitem que as análises de temperatura de superfície possam ser realizadas com a utilização da metodologia que possibilita a aquisição de valores de temperatura de superfície da Zona Central de Umuarama, Paraná, que foram esboçadas nos mapas termais.

\section{CONCLUSÃO}

Com a correlação entre as temperaturas, uso do solo e vegetação, foi possível identificarmos a discrepância das temperaturas de oeste em relação a leste da desta área. $\mathrm{Na}$ porção a oeste as temperaturas foram superiores em todas as imagens, devido ao uso e ocupação do solo, materiais utilizados nas construções, morfologia urbana, como também do baixo índice de vegetação.

Contudo, deve-se deixar claro que este trabalho analisou somente a temperatura de superfície e não os fenômenos Ilhas de calor e Ilhas de frescor, pois estes fenômenos demandam temperatura do ar próxima ao solo. Neste contexto, os estudos de temperatura de superfície podem auxiliar em planos diretores e, principalmente, no planejamento urbano, de modo que possa mitigar a ascensão da temperatura de superfície.

Como sugestão para amenizar a temperatura de superfície na Zona Central de Umuarama-PR, é necessário intensificar a arborização na Praça Oscar Thompson Filho, pois a arborização irá contribuir com o arrefecimento da localidade. Recomendamos que sejam utilizadas árvores de grande porte como as da Família Fabaceae - Tipuana (Tipuana tipu) e Sibipiruna (Caesalpinia pluviosa), que apresentam grande porte na fase adulta, podendo formar dossel avantajado, proporcionando amplo sombreamento.

Além da arborização, os gestores e planejadores do município poderão encarregar-se de restringir alguns materiais e cores (como exemplo a cor de tinta preta e entre outras) de 
tinta que intensificam o aumento da temperatura de superfície e, também materiais como aço galvanizado e teto de zimco e alumínio.

Por fim, conseguimos provar também neste estudo que o uso das geotecnologias, é fundamental nas tomadas de decisões, planos de ações e no auxílio à gestão urbana. Assim, as geotecnologias quando bem empregadas contemplam melhorias para as cidades, mas principalmente para a sociedade que cotidianamente mantém o fluxo de bens e serviços nas áreas urbanas.

\section{AGRADECIMENTOS}

Os autores agradecem o suporte financeiro e incentivo à pesquisa da Fundação CAPES. Agradecimentos ao Prof. Dr. Valdeir Demétrio da Silva, pelo apoio. Agradecemos também aos avaliadores que contribuíram para a melhoria do trabalho.

\section{REFERÊNCIAS}

ARNFIELD, A. John. Two decades of urban climate research: a review of turbulence, exchanges of energy and water, and the urban heat island. International Journal of Climatology, v. 23, 1-26, 2003.

EDUVIRGEM, Renan Valério; FERREIRA, Maria Eugênia Moreira Costa. Aspectos quantitativos e qualitativos dos equipamentos e estruturas existentes nas Praças Arthur Thomas e Juscelino Kubitschek. In: II Simpósio Brasileiro sobre Governança e Desenvolvimento Sustentável, p. 31-43. 2017.

FITZ, Paulo Roberto. Cartografia básica. São Paulo: Oficina de Textos, 2008.

GARCIA, Felipe Fernandez. Manual de climatologia aplicada. Madrid: Editorial Sintesis, 1996.

GERMANO, Paulo José Moraes Monteiro e Teixeira. Investigação Multitemporal de Ilhas de Calor e de Frescor em Maringá, Paraná, Utilizando Imagens do Satélite Landsat 2000 a 2010, 2012. 109 f. (Dissertação de Mestrado). Maringá: Programa de Pós Graduação em Engenharia Urbana - Universidade Estadual de Maringá. 2012.

GERTLAND, Lisa. Ilhas de Calor: como mitigar zonas de calor em áreas urbanas. Tradução: Silvia Helena Gonçalves. São Paulo: Oficina de Textos 2010.

GREY, G. W; DENEKE, F. J. Urban forestry. New York; John Wiley, 1978.

IAPAR. Instituto Agronômico do Paraná, Cartas Climáticas do Paraná. Londrina, 2000. 45p. 
IBGE. Instituto Brasileiro de Geografia e Estatística, Cidades. Disponível em: $<$ https://cidades.ibge.gov.br/brasil/pr/umuarama/panorama>. Acesso em 09/02/2018.

IBGE. Instituto Brasileiro de Geografia e Estatística, Mapa de clima do Brasil. Disponível em:<ftp://geoftp.ibge.gov.br/informacoes_ambientais/climatologia/mapas/brasil/clima.pdf $\rangle$. Acesso em 10/02/2018.

KUTTLER, W. Spatial and temporal structures of the urban climate - a survey. In K. GREFEN and J. LOBEL - Environmental Meteorology. Kluwer Academic Publishers, Dordrecht, 305-344, 1988.

LANDSBERG, H. E. The urban climate. Academic Press, New York. 1981.

LOMBARDO, Magda Adelaide. Ilha de Calor nas Metrópoles. Ed. Hucitec, São Paulo, 1985.

MAACK, Reinhard. Geografia física do estado do Paraná. 1ed. Curitiba, Paraná. Banco de desenvolvimento do Paraná, Universidade Federal do Paraná e Instituto de Biologia e Pesquisas tecnológicas, 1968. 350p.

MONTEIRO, Carlos Augusto de Figueiredo. Clima Urbano. São Paulo: Editora Contexto, 2003.

OKE, T. R. Boundary layer climates. Routledge, London, 1987.

OKE, T. R. The urban energy balance. Progress in Physical Geography, v. 12, n. 4, 471508, 1988.

QUANTUM GIS DEVELOPMENT TEAM. Quantum GIS Geographic Information System. Open Source Geospatial Foundation Project, 2012. Disponível em: <http://qgis.osgeo.org>. Acesso em 15/04/2018.

SZINVELSKI, Ildo Mário. A poluição veicular ambiental: aspectos legais. Monografia de Especialista em Direito Ambiental. Universidade Luterana do Brasil - ULBRA. Canoas, RS, Janeiro de 2005, 152p.

TUBELIS, Antônio; NASCIMENTO, Fernando José Lino. Meteorologia descritiva: fundamentos e aplicações brasileiras. São Paulo: Nobel, 1984.

USGS. United States Geological Survey. Earth Explorer. Disponível em: <https://earthexplorer.usgs.gov/>. Acesso em 05/02/2015.

WENG, Qihao; QUATTROCHI, Dale A. Thermal remote sensing of urban areas: An introduction to the special issue. Remote Sensing of Environment. p. 119-122. 2003.

YALE UNIVERSITY. EARTH OBSERVATORY - Converting Landsat TM and ETM+ thermal bands to temperature. 2008. Disponível em <http://www.yale.edu/ceo/> Acesso em 22/08/2015. 